\title{
Adsorption properties and breakthrough model of 1,1-dichloro-1-fluoroethane on activated carbons
}

\author{
Wen-Tien Tsai ${ }^{\mathrm{a}, *}$, Ching-Yuan Chang ${ }^{\mathrm{b}}$, Chih-Yin Ho ${ }^{\mathrm{b}}$, \\ Lu-Yen Chen ${ }^{\mathrm{b}}$
}

${ }^{\text {a }}$ Department of Environmental Engineering and Health, Chia Nan College of Pharmacy and Science, Tainan 717, Taiwan, ROC

${ }^{\mathrm{b}}$ Graduate Institute of Environmental Engineering, National Taiwan University, Taipei 106, Taiwan, $R O C$

Received 22 February 1999; accepted 24 April 1999

\begin{abstract}
Hydrochlorofluorocarbons (HCFCs), among the major replacements for chlorofluorocarbons (CFCs) and chlorinated solvents, are now considered to the prime contribution to the stratospheric ozone depletion. This paper reports the adsorption equilibrium of 1,1-dichloro-1-fluoroethane (HCFC-141b) vapor in air streams on the commercial activated carbons PCB and BPL, which were made from coconut shell and bituminous coal, respectively, at 283, 293, 303, and $313 \mathrm{~K}$. The experimental results show that within the experimental conditions, the adsorption capacities of the two adsorbents for HCFC-141b in dry air streams can be well-fitted by the Langmuir, Freundlich, and Dubinin-Radushkevich (D-R) adsorption equations. The physical properties of the adsorbents are consistent with the isotherm parameters obtained from the adsorption results. In addition, available experimental data of adsorption breakthrough at $283 \mathrm{~K}$ were used in conjunction with the Yoon and Nelson model to generate theoretical breakthrough curves based on the obtained values of parameters. In each case, calculated theoretical breakthrough curves are in agreement with corresponding experimental data. (C) 1999 Elsevier Science B.V. All rights reserved.
\end{abstract}

Keywords: HCFC-141b; Activated carbons; Adsorption isotherm; Breakthrough

\section{Introduction}

In recent years, it has been reported that the chlorine contained in chlorofluorocarbons (CFCs), halogenated carbons and hydrochlorofluorocarbons (HCFCs) are the

\footnotetext{
* Corresponding author.
} 
primary agents responsible for the observed depletion of stratospheric ozone [1-3]. The HCFCs are being developed as interim replacements for the CFCs [4,5]. According to the Montreal Protocol, all HCFCs will be gradually phased out by 2030 [2]. While good replacement compounds of HCFCs may not be readily available within the next few years. As a result, it is expected that the recovery and recycle of HCFCs will become extremely important in the near future.

1,1-Dichloro-1-fluoroethane (HCFC-141b) has been widely used as an excellent cleaning solvent (i.e. replacement for CFC-113) in the electronics industry and as a foaming agent (i.e. replacement for $\mathrm{CFC}-11$ ) in the polyurethane (PU) insulation industry [6]. However, as the compound is very volatile, losses due to work place emissions in a typical plant can be as high as $100 \%$ [7]. Alternatives to this compound are being looked for. Some alternatives (e.g. hydrofluorocarbons, HFCs), however, also have a detrimental effect on the environment, such as contribution to the greenhouse effect and the toxicity to occupational workers $[5,8,9]$.

Adsorption, absorption, and condensation are three common technologies for the recovery or recycle of volatile organic compounds (VOC) from gas streams generated by small industrial source [10]. Because it provides a much more economical way to recover VOC from a wide range of gas streams, adsorption is by far the most widespread technology for VOC recovery [10-12].

Gas-phase adsorption is a separation process in which adsorbate molecules are transferred to the pore surface of solid adsorbents. Activated carbon adsorption has been utilized for many years to recover solvent vapors in areas such as dry cleaning, degreasing electronics, and film coating [13]. Activated carbon is a predominantly amorphous solid that has a large internal surface area and pore volume. The main base materials for the granular activated carbon (GAC) adsorbent for gas-phase applications include bituminous coal and coconut shell [14-16]. Coconut-based carbon has a high density and a large number of extremely small pores. Carbon from bituminous coal, on the other hand, has superior hardness and broad pore size distribution as well as large content of ash [17,18].

Few discussions were made in the literature about adsorption behavior of HCFC-141b on activated carbon. Logsdon and Basu [19] studied the feasibility of carbon adsorption process for the recovery of HCFC-141b at about $298 \mathrm{~K}$ and feed concentrations of 500, 825, and $1020 \mathrm{ppm}$ in nitrogen streams. Lin and Chen [6,20] and Lin et al. [21] examined the adsorption characteristics of HCFC-141b by various adsorbents in a closed space (i.e. flask), including equilibrium adsorption capacity, and time to reach equilibrium. They showed that carbon adsorbents are very good adsorbents for HCFC-141b recovery, and the HCFC-141b adsorption capacity can be described only well by the Freundlich isotherm compared with the Langmuir isotherm. Tanada et al. [22] investigated the adsorption properties of CFC-113 and CFC replacements (e.g. HCFC-141b) on several kinds of plasma-treated activated carbons. Experimental data were correlated well by the Dubinin-Radushkevich (D-R) equation.

Fixed-bed adsorption has been used widely in separation and purification of vent gases [23]. To design such an adsorption process, it is important to understand the adsorption capacities and adsorption kinetics characteristics between the adsorbent and adsorbate. One way to obtain these characteristics is by examining the concentration vs. 
time curves of the effluent. The breakthrough curve and the adsorption equilibrium are perhaps the most common basis for assessing the behavior of the adsorption process.

In this paper, we describe the adsorption capacities of HCFC-141b on commercial activated carbons at different inlet concentrations (i.e. 350-2000 ppm) and equilibrium temperatures (i.e. 283-313 K). These experimental conditions are typically selected for the design of a VOC recovery system [10]. By regression of the experimental results, we also report the effect of adsorbate concentration on the adsorption capacity based on the applicability of various common isotherm equations, such as, Langmuir, Freundlich, and Dubinin-Radushkevich (D-R) equations [24,25]. In addition, the theoretical breakthrough curves at equilibrium temperature of $283 \mathrm{~K}$ and five different inlet concentrations (i.e. 350-2000 ppm) are generated and studied to compare with the corresponding experimental data using Yoon and Nelson model which gives an equation predicting the whole breakthrough curve [26].

\section{Materials and methods}

Two different kinds of the commercial granular activated carbons produced from coconut shell, PCB, and bituminous coal, BPL, were obtained from Calgon Carbon (Pittsburgh, USA). The activated carbons were sieved to mesh ranges of 20-30 (average particle diameter of $0.718 \mathrm{~mm})$ and dried at $378 \mathrm{~K}$ in a vacuum dryer $\left(10^{-2}-10^{-3} \mathrm{~mm}\right.$ $\mathrm{Hg}$ ) for at least $24 \mathrm{~h}$ and then stored in a desiccator, before being used in the experiments. The physical properties of these adsorbents were measured and determined by the Brunauer-Emmett-Teller (BET) method and $t$-plot method [25]. The results were given as follows: BET surface area, 1012 and $1028 \mathrm{~m}^{2} / \mathrm{g}$; micropore (i.e. pore diameter $<20 \AA$ ) surface area, 853 and $621 \mathrm{~m}^{2} / \mathrm{g}$; micropore (i.e. pore diameter $<20$ $\AA$ ) volume, 0.407 and $0.286 \mathrm{~cm}^{3} / \mathrm{g}$; and true density, 2.218 and $2.235 \mathrm{~g} / \mathrm{cm}^{3}$ for adsorbents BPL and PCB, respectively. HCFC-141b used as adsorbate gas for adsorption was obtained from Allied Signal (NJ, USA) with a minimum purity of $99.5 \%$.

The schematic diagram of the experimental apparatus has been reported previously [7]. The adsorption column is made of Pyrex glass and has an inner diameter of $15 \mathrm{~mm}$ and a length of $250 \mathrm{~mm}$. The dried inlet feed ( $<3 \%$ relative humidity) was controlled using a mass flow controller and bubbled through a liquid adsorbate (i.e. HCFC-141b) in the impinger tube, which was contained in a thermostatic water bath, to vaporize the VOC. The VOC-rich air was then mixed with a main purified air stream and the mixture gas passed through about $2 \mathrm{~m}$ reheat and/or recool coil to reach the adsorption temperature to a preset value. Concentration of HFCF-141b in the mixed stream could be adjusted by varying the temperature of the liquid adsorbate and the relative flow rates of VOC-rich air and the main air stream. The coil and the adsorbent column were located in a thermostatic water bath in which a certain temperature could be maintained.

A sample of 2.5-3.5 $\mathrm{g}$ of the dried adsorbent was packed into the column for each test. The packed column was weighed by a microbalance (Sartorius, Germany; Model No. R200D), and then set into the thermostatic bath. At the same time, the temperature of the thermostatic bath was adjusted to a desired value (i.e. 283, 293, 303, and $313 \mathrm{~K}$ ). It took approximately 1-2 $\mathrm{h}$ for the system to reach a steady-state condition, as judged 
from nearly constant VOC concentration both in influent and effluent air. The concentration of HCFC-141b vapors at the inlet of the adsorption column was set at a certain value ranging from 350 to $2000 \mathrm{ppm}$. After the column was at steady-state condition, air with desired VOC concentration was introduced into the column at an approximate rate of $2900 \mathrm{~cm}^{3} / \mathrm{min}$ measured at standard conditions (298 $\mathrm{K}$ and $\left.1 \mathrm{~atm}\right)$.

In order to obtain the breakthrough curves of adsorption at $283 \mathrm{~K}$, a small amount (i.e. $0.1 \mathrm{~cm}^{3}$ ) of the effluent gas of HCFC-141b vapor/air was taken with a gas-tight microsyringe at suitable time intervals (i.e. $2-10 \mathrm{~min}$ ) and analyzed by gas chromatography as described below. When the effluent concentration of the adsorbate reached the influent concentration (i.e. $100 \%$ of breakthrough), the concentration measurement of the effluent gas was terminated. The gas flow through the adsorption column was continued for an additional $30 \mathrm{~min}$ to ensure that adsorption equilibrium was reached. After the system at equilibrium, the column was taken from the experimental system, wiped, and weighed again. The adsorbed mass of HCFC-141b vapor in equilibrium with the inlet concentration at the specified adsorption temperature was determined as the mass difference of the column before and after adsorption. The mass differences measured in this study were small in some cases (approximately $0.1 \mathrm{~g}$ ). Hence, the microbalance for mass measurement has a sensitivity of $0.1 \mathrm{mg}$, and which introduces a very low relative error.

The concentration of HCFC-141b in the gas samples was measured by a gas chromatograph (GC-5890 Series II, Hewlett-Packard, USA) with a packed column (2.0 $\mathrm{mm}$ i.d. and $3 \mathrm{~m}$ long packed with 60/80 Carbopack B 15\% Fluorcol; Supelco, USA). The instrument was equipped with a flame ionization detector (FID). The temperatures of the oven, the injection well and the FID were kept at 453, 473, and $523 \mathrm{~K}$, respectively. The flow rates of nitrogen, hydrogen and air were set at 30, 33 and 412 $\mathrm{cm}^{3} / \mathrm{min}(1 \mathrm{~atm}$ and $298 \mathrm{~K}$ ). Relative humidity of the air stream was monitored by a humidity-thermal meter (HMP35, Vaisala, Finland), in the range of less than $3 \%$ for all experimental runs.

The reproducibility analysis of HCFC-141b vapor concentration was made at the influent concentration of approximately $1950 \mathrm{ppm}$. The value of $1950.31 \pm 33.80 \mathrm{ppm}$ (i.e. mean \pm standard deviation) was obtained for 12 samples. Also, the reproducibility analysis of adsorption capacity was determined at the influent concentration of 1210 ppm and the adsorption temperature of $293 \mathrm{~K}$. The value of $0.2835 \pm 0.0002 \mathrm{~g} / \mathrm{g}$ (mass of adsorbate/mass of adsorbent) was obtained for five experimental runs.

\section{Results and discussion}

\subsection{Adsorption equilibrium}

There are various isotherm equations ranging almost fully empirical to largely theoretical in the adsorption literature. Among them, the simplest and still useful isotherm is the Langmuir equation, which is based on constant adsorption energy independence of surface coverage. When the adsorption equilibrium data do not fit well on linear coordinates, the Freundlich isotherm is probably the equation most commonly 
used. In isotherm equations employing the adsorption potential, the pore-type parameter can be raised to different powers that empirically related to the characteristics of pores in the adsorbent. The Dubinin-Radushkevich (D-R) isotherm uses an exponent of 2, which has been found appropriate for microporous adsorbents as used in the present study. Because these three isotherms provide their respective information useful for adsorption, we thus present their results for reference.

In order to assist the process design of such adsorption facilities, it is important to establish the most appropriate correlation for the adsorption equilibrium curves. Three isotherm equations have been tested in the present study: Langmuir, Freundlich, and Dubinin-Radushkevich (D-R) models described as follows.

\subsubsection{Langmuir model}

The most widely used isotherm equation for modeling adsorption equilibrium data is the Langmuir equation [27,28], written as

$$
\frac{q}{q_{\mathrm{m}}}=\frac{K_{\mathrm{L}} C}{1+K_{\mathrm{L}} C},
$$

where $q$ is the adsorption capacity $(\mathrm{mol} / \mathrm{kg}), q_{\mathrm{m}}$ is the maximum adsorption capacity $(\mathrm{mol} / \mathrm{kg}), C$ is the adsorbate equilibrium concentration $\left(\mathrm{mol} / \mathrm{m}^{3}\right)$, and $K_{\mathrm{L}}$ is the Langmuir constant or adsorption equilibrium constant $\left(\mathrm{m}^{3} / \mathrm{mol}\right)$. The constants $q_{\mathrm{m}}$ and $K_{\mathrm{L}}$ are the characteristics of the Langmuir equation and can be determined from a linear regression of $1 / q$ vs. $1 / C$ for each set of experimental data. The heat of adsorption was assumed to be independent of temperature and was evaluated by the vant Hoff equation [14,28,29]:

$$
K_{\mathrm{L}}=k_{\mathrm{a}} \exp \left(\frac{-\Delta H}{R T}\right),
$$

where $\Delta H$ is the heat of adsorption $(\mathrm{J} / \mathrm{mol})$, and $k_{\mathrm{a}}$ is the nature of a frequency factor $\left(\mathrm{m}^{3} / \mathrm{mol}\right)$.

The Langmuir constants, $q_{\mathrm{m}}$ and $K_{\mathrm{L}}$, have been determined for all the systems studied, and are shown in Table 1. As shown in Table 1, the experimental data could be

Table 1

Parameters of Langmuir isotherm and vant Hoff equation for adsorption of HCFC-141b on adsorbents BPL

\begin{tabular}{|c|c|c|c|c|c|c|c|}
\hline \multirow[t]{2}{*}{ Adsorbent } & \multirow{2}{*}{$\begin{array}{l}\text { Equilibrium } \\
\text { temperature }(\mathrm{K})\end{array}$} & \multicolumn{2}{|c|}{ Langmuir parameters } & \multirow[t]{2}{*}{$R^{2}$} & \multicolumn{2}{|c|}{ vant Hoff parameters } & \multirow[t]{2}{*}{$R^{2}$} \\
\hline & & $\overline{q_{\mathrm{m}}(\mathrm{mol} / \mathrm{kg})}$ & $K_{\mathrm{L}}\left(\mathrm{m}^{3} / \mathrm{mol}\right)$ & & $\overline{\Delta H(\mathrm{~kJ} / \mathrm{mol})}$ & $k_{\mathrm{a}}\left(\mathrm{m}^{3} / \mathrm{mol}\right)$ & \\
\hline \multirow[t]{4}{*}{ PCB } & 283 & 3.11 & 104.92 & 0.9562 & & & \\
\hline & 293 & 2.92 & 100.90 & 0.9821 & & & \\
\hline & 303 & 2.55 & 83.31 & 0.9697 & -12.70 & 0.59 & 0.8993 \\
\hline & 313 & 2.15 & 77.14 & 0.9686 & & & \\
\hline \multirow[t]{4}{*}{ BPL } & 283 & 2.30 & 131.91 & 0.9506 & & & \\
\hline & 293 & 2.09 & 122.79 & 0.9653 & & & \\
\hline & 303 & 1.84 & 104.52 & 0.9469 & -12.53 & 0.73 & 0.9148 \\
\hline & 313 & 1.64 & 79.18 & 0.9841 & & & \\
\hline
\end{tabular}
and PCB at various temperatures 
reasonably fitted by the Langmuir equation with correlation coefficients $\left(R^{2}\right)$ in the range of $0.95-0.98$. The values of $\Delta H$ for HCFC-141b adsorption system, computed from Eq. (2), are also listed in Table 1. Table 1 indicates that the maximum adsorption capacity, $q_{\mathrm{m}}$, and Langmuir constant, $K_{\mathrm{L}}$, for both adsorbents decrease with increasing equilibrium adsorption temperature as expected. This tendency is reasonable since the activated carbon adsorption is exothermic (i.e. $\Delta H<0$, as shown in Table 1), and adsorption affinity will be reduced at higher temperatures. Table 1 also indicates that the adsorption capacity of adsorbent PCB is higher than that of adsorbent BPL. This supports that the micropore volume (i.e. $0.407 \mathrm{~cm}^{3} / \mathrm{g}$ ) of adsorbent PCB is larger than that (i.e. $0.286 \mathrm{~cm}^{3} / \mathrm{g}$ ) of adsorbent BPL.

\subsubsection{Freundlich model}

The Freundlich isotherm equation is an empirical equation and may be derived by assuming a heterogeneous surface with adsorption on each class of sites that obeys the Langmuir equation [14]. According to the Freundlich equation, the amount adsorbed increases infinitely with increasing concentration [30]. This equation is, therefore, satisfactory for low concentration. The Freundlich equation is commonly used as

$$
q=K_{\mathrm{F}} C^{1 / n},
$$

where $q$ and $C$ are as defined in Eq. (1) and $K_{\mathrm{F}}$ and $n$ are empirical constants, which depend on the nature of adsorbent and adsorbate, and on the temperature. Eq. (3) may be linearized by taking logarithms. Therefore, a plot of $\ln q$ vs. $\ln C$ enables the empirical constants $K_{\mathrm{F}}$ and $n$ to be determined from the intercept and slope of the linear regression plot. In general, $n$ has a value greater than unity [31]. The Freundlich parameters, $K_{\mathrm{F}}$ and $n$, were thus determined and listed in Table 2. Obviously, there is good correlation between Freundlich model predications and the experimental data, and almost the values of $K_{\mathrm{F}}$ decrease with increasing temperature.

It has been known that the magnitude of $K_{\mathrm{F}}$ indicates a measure of the adsorbent capacity [32]. As indicated in Table 2, the values of the exponent $n$ were in the range of 3-6, indicating favorable adsorption. Also, the values of $K_{\mathrm{F}}$ of adsorbent PCB are larger than those of adsorbent BPL at the same temperature. This is consistent with the

Table 2

Freundlich parameters for adsorption of HCFC-141b on adsorbents PCB and BPL at various temperatures

\begin{tabular}{|c|c|c|c|c|}
\hline \multirow[t]{2}{*}{ Adsorbent } & \multirow{2}{*}{$\begin{array}{l}\text { Adsorption } \\
\text { temperature (K) }\end{array}$} & \multicolumn{2}{|c|}{ Freundlich parameters } & \multirow[t]{2}{*}{$R^{2}$} \\
\hline & & $\overline{K_{\mathrm{F}}}$ & $n$ & \\
\hline \multirow[t]{4}{*}{$\overline{\mathrm{PCB}}$} & 283 & 4.77 & 5.25 & 0.9958 \\
\hline & 293 & 5.08 & 3.97 & 0.9985 \\
\hline & 303 & 4.81 & 3.51 & 0.9981 \\
\hline & 313 & 4.28 & 3.28 & 0.9988 \\
\hline \multirow[t]{4}{*}{ BPL } & 283 & 3.58 & 4.99 & 0.9973 \\
\hline & 293 & 3.37 & 4.65 & 0.9991 \\
\hline & 303 & 3.27 & 3.94 & 0.9950 \\
\hline & 313 & 3.23 & 3.28 & 0.9977 \\
\hline
\end{tabular}


results based on the Langmuir analysis, i.e. the adsorbent PCB has higher capacity for HCFC-141b vapor than adsorbent BPL. This is due to the substantial difference in the micropore volume of adsorbents used in the present study. However, the BET surface areas of adsorbents PCB and BPL approximate to each other.

\subsubsection{Dubinin-Radushkevich (D-R) model}

According to the Polanyi theory [28,32,33], the adsorption equilibrium relation for a given adsorbate-adsorbent system can be expressed independent of temperature by using the adsorption potential. Thus

$$
W=q / \rho=f(A),
$$

where $W$ is the volume of micropore filled by the adsorbate $\left(\mathrm{cm}^{3} / \mathrm{g}\right), \rho$ is the density of the adsorbed phase $\left(\mathrm{g} / \mathrm{cm}^{3}\right)$, and $A$ is defined as adsorption potential $(\mathrm{J} / \mathrm{mol})$, as expressed by

$$
A=R T \ln \left(P_{\mathrm{s}} / P\right),
$$

where $P_{\mathrm{s}}$ is the saturated pressure of liquid adsorbate at the adsorption temperature $T$, and $P$ is the pressure of adsorbate vapor in equilibrium with the adsorbed liquid film. It has been assumed a distribution of the Gaussian type for $f(A)$ and derived the following, which is called Dubinin-Radushkevich (D-R) equation [33]:

$$
W=W_{\mathrm{o}} \exp \left(-\kappa \frac{A^{2}}{\beta^{2}}\right),
$$

where $W_{\mathrm{o}}$ is considered to correspond to the micropore volume of adsorbent $\left(\mathrm{cm}^{3} / \mathrm{g}\right), \kappa$ is a characteristic parameter related to the pore structure of adsorbent $\left(\mathrm{mol}^{2} / \mathrm{J}^{2}\right)$, and $\beta$ is an affinity coefficient (i.e. similarity constant) which permits the comparison of the adsorption potential of the test adsorbate to a reference adsorbate (e.g. benzene). The value of $\beta$ has been correlated by several physical properties such as liquid molar volume, molecular parachors, and electronic polarization [14]. For polar adsorbates (e.g. HCFC-141b), it was pointed out that the ratio of the electronic polarizations, $P_{\mathrm{e}}$ $\left(\mathrm{cm}^{3} / \mathrm{mol}\right)$, can be used to calculate the affinity coefficient [34]. The electronic polarization and affinity coefficient are thus given by

$$
\begin{aligned}
& P_{\mathrm{e}}=\frac{\left(n_{\mathrm{r}}^{2}-1\right) M}{\left(n_{\mathrm{r}}^{2}+2\right) \rho} \\
& \beta=\frac{P_{\mathrm{e}}}{\left(P_{\mathrm{e}}\right)_{\mathrm{ref}}},
\end{aligned}
$$

where $n_{\mathrm{r}}$ is the refractive index of the liquid adsorbate, $M$ is the molecular weight of the adsorbate $(\mathrm{g} / \mathrm{mol})$, and $\rho$ is the density of the liquid adsorbate $\left(\mathrm{g} / \mathrm{cm}^{3}\right)$. The physical parameters in Eq. (7) can be obtained from the Handbook of Chemistry and Physics [35], and others references [36,37].

Fig. 1 illustrates the typical D-R plots as $\ln W$ vs. $A^{2}$ for adsorbents PCB and BPL. The parameters $\kappa$ and $W_{\mathrm{o}}$ in the D-R equation were obtained from the best fit with the slope $-\kappa / \beta^{2}$, and the intercept $\ln W_{\mathrm{o}}$, employing least square analysis. The values of 

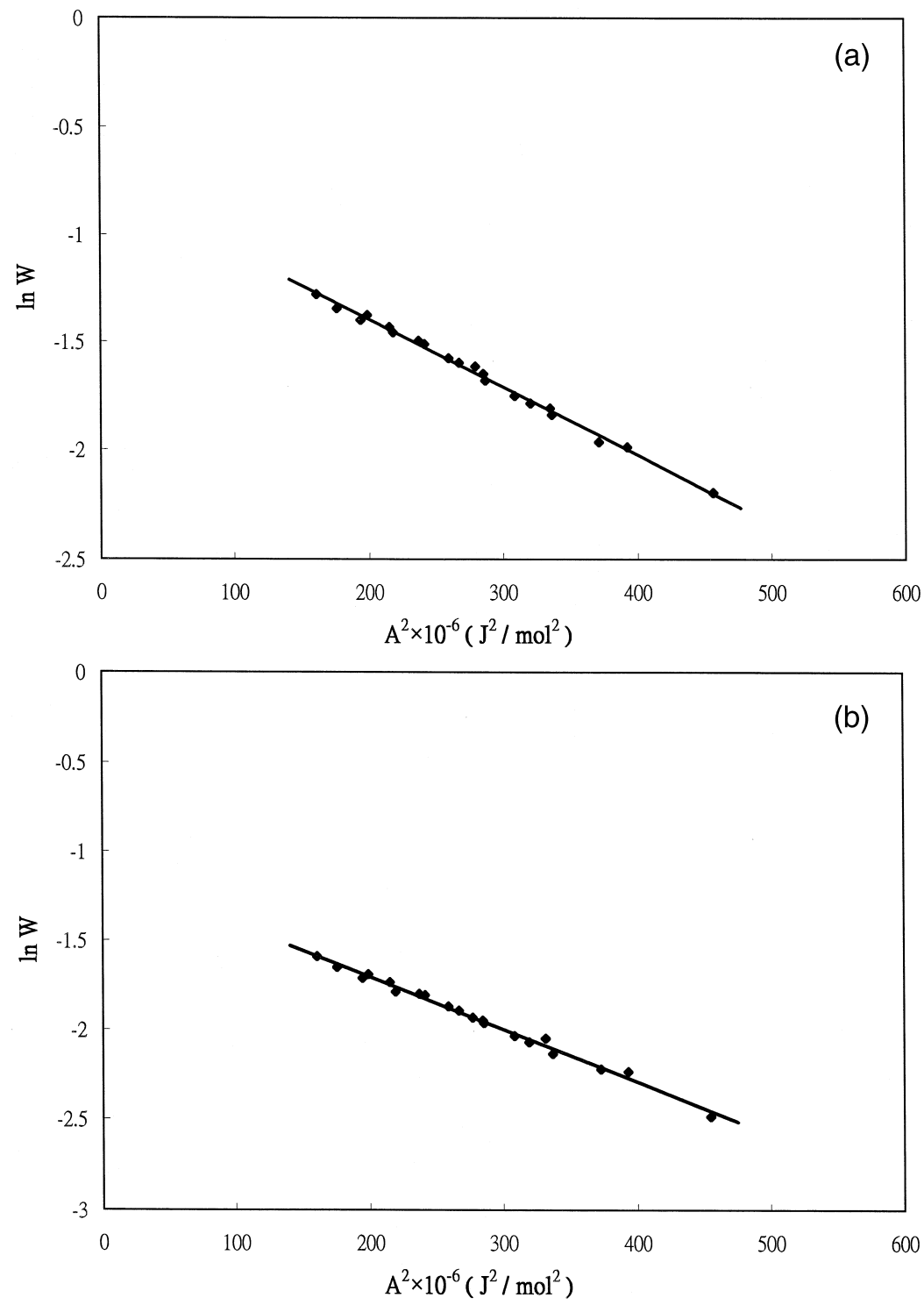

Fig. 1. Correlations of Dubinin-Radushkevich (D-R) equation for HCFC-141b adsorption on activated carbons (a) PCB $\left(R^{2}=0.9950\right)$ and (b) BPL $\left(R^{2}=0.9918\right)$ [symbols: experimental data; full lines: calculated from Eqs. (5) and (6)].

$W_{\mathrm{o}}$ and $\kappa$ for the two activated carbons are summarized in Table 3. Several noteworthy features may be obtained from the results shown in Table 3 . The value of $W_{\mathrm{o}}$ of adsorbent PCB is larger than that of adsorbent BPL, supporting the fact that adsorbent PCB contains more micropore volume. This is also consistent with the measured values (i.e. 0.407 and $0.286 \mathrm{~cm}^{3} / \mathrm{g}$, respectively) of micropore volume of adsorbents PCB and 
Table 3

D-R equation parameters for adsorption of HCFC-141b $\mathrm{b}^{\mathrm{a}}$

\begin{tabular}{llll}
\hline Adsorbent & $W_{\mathrm{o}}\left(\mathrm{cm}^{3} / \mathrm{g}\right)$ & $\kappa\left(\mathrm{mol}^{2} / \mathrm{J}^{2}\right)$ & $R^{2}$ \\
\hline PCB & 0.4641 & $2.08 \times 10^{-9}$ & 0.9950 \\
BPL & 0.3271 & $1.95 \times 10^{-9}$ & 0.9918 \\
\hline
\end{tabular}

${ }^{\mathrm{a}}$ Value of $\beta$ of HCFC-141b is 0.82 .

BPL. It should be noted that the values of micropore volume were measured for micropores in the range of $15-20 \AA$ only because of the limitation of the analytical instrument [25]. Therefore, the measured micropore volumes are less than the computed values of $W_{\mathrm{o}}$ from Eq. (6).

\subsection{Modeling adsorption breakthrough}

Many theoretical or empirical equations have been proposed for modeling adsorption breakthrough curves $[38,39]$. These equations were theoretically addressed to describe the adsorbate diffusion in the porous adsorbent (e.g. activated carbon). It has been reported that breakthrough times (i.e. time to reach defined effluent concentrations) and adsorption capacities (i.e. amounts held at breakthrough) of adsorbent beds for a given adsorbate vapor are functions of the concentration of that vapor in air [26]. Yoon and Nelson [26] have developed a relatively simple model addressing the adsorption and breakthrough of adsorbate vapor with respect to activated charcoal. This model was based on the assumption that the rate of decrease in the probability of adsorption for each adsorbate molecule is proportional to the probability of adsorbate adsorption and the probability of adsorbate breakthrough on the adsorbent. Yoon and Nelson equation is not only less complicated than other equations such as the Wheeler equation [40] and Mecklenburg equation [41], but also requires no detailed data concerning the characteristics of adsorbate, the type of adsorbent, and the physical properties of adsorption bed. Therefore, Yoon and Nelson equation is tentatively applied in this study to describe the breakthrough curves for adsorption of HCFC-141b vapor on adsorbents PCB and BPL at temperature of $283 \mathrm{~K}$.

The Yoon and Nelson equation pertaining to a single-component system is expressed as

$$
\begin{aligned}
& t=\tau+\frac{1}{k^{\prime}} \ln \frac{C_{\mathrm{b}}}{C_{\mathrm{i}}-C_{\mathrm{b}}} \\
& k=k^{\prime} \tau,
\end{aligned}
$$

where $k^{\prime}$ is the rate constant $(1 / \mathrm{min}), \tau$ is the time required for $50 \%$ adsorbate breakthrough ( $\mathrm{min}), t$ is the breakthrough (sampling) time (min), $C_{\mathrm{b}}$ is the breakthrough (effluent) concentration of adsorbate (ppm), $C_{\mathrm{i}}$ is the initial (inlet) concentration of adsorbate (ppm), and $k$ is the proportionality constant. The calculation of theoretical breakthrough curves for a single-component system requires the determination of the parameters $k^{\prime}$ and $\tau$ for the adsorbate of interest. These values may be determined from 
available experimental data. The approach involves a plot of $\ln \left[C_{\mathrm{b}} /\left(C_{\mathrm{i}}-C_{\mathrm{b}}\right)\right]$ vs. sampling time $(t)$ according to Eq. (9). If the theoretical model accurately characterizes the experimental data, this plot will result in a straight line with slope of $k^{\prime}$ and intercept of $-k^{\prime} \tau(=-k)$. The value of $\tau$ may, therefore, be determined from the intercept and slope of the plot.
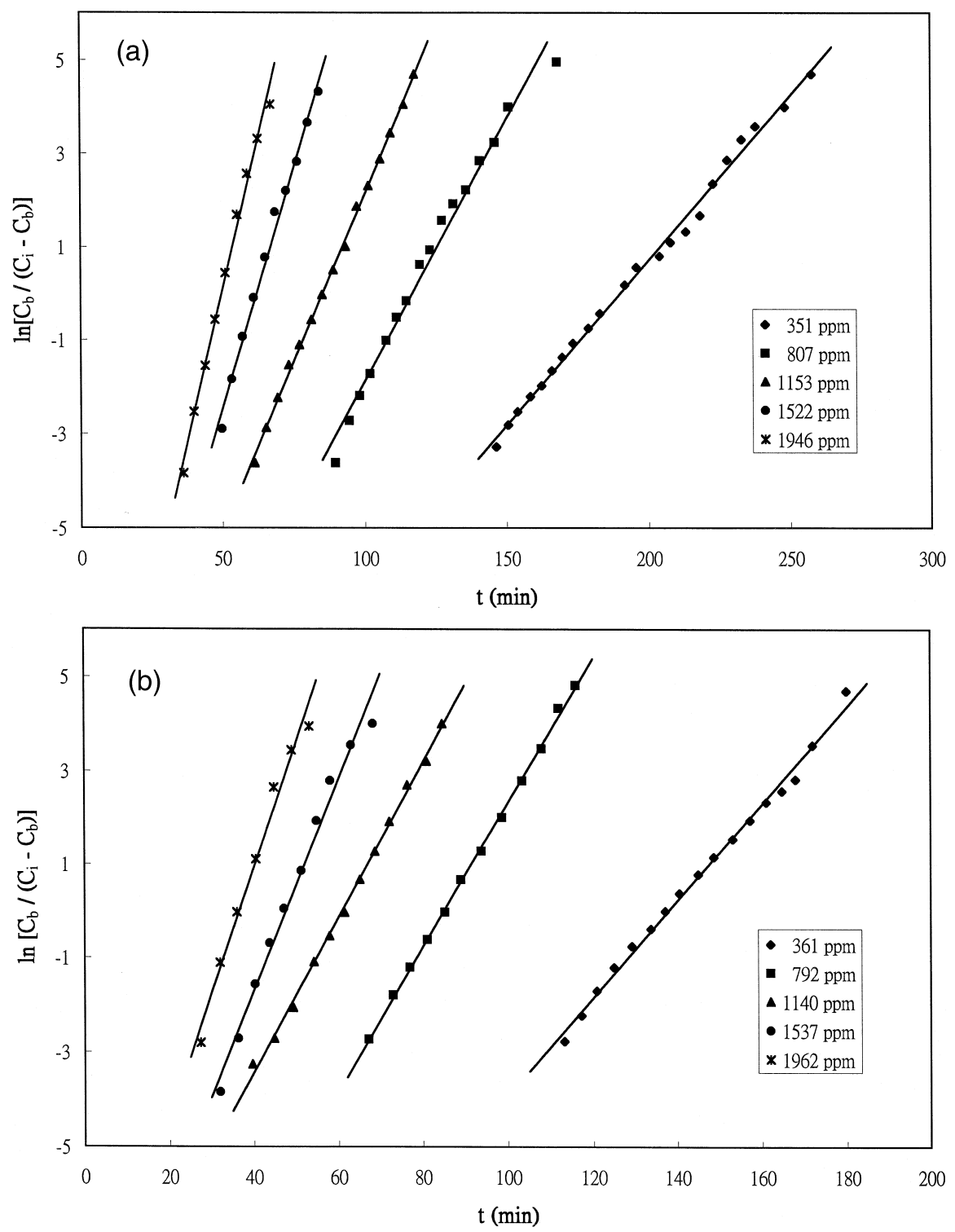

Fig. 2. Plots of $\ln \left[C_{\mathrm{b}} /\left(C_{\mathrm{i}}-C_{\mathrm{b}}\right)\right]$ vs. $t$ for various concentrations of HCFC-141b adsorption on activated carbons (a) PCB and (b) BPL [symbols: experimental data; full lines: calculated from Eq. (9)]. 
In the current study for the adsorption of HCFC-141b on adsorbents PCB and BPL, the inlet concentration of HCFC-141b was in the range of 351-1946 ppm and 361-1962 ppm, respectively. These values were applied to calculate the values of $k^{\prime}, \tau$, and $k$ at each concentration. The results by applying Eq. (9) at various HCFC-141b concentrations are shown in Fig. 2. As predicted [26], the plots yield straight lines with the slope of $k^{\prime}$ and the intercept of $-k$. Obviously, the model appears to fit the experimental data reasonably well. The regression analysis (least square method) has been used to give the model parameters of $k$ and $\tau$ as listed in Table 4. As expected [26], both $k^{\prime}$ and $\tau$ are dependent on the adsorbate inlet concentration. The value of $\tau$ decreases with increasing adsorbate inlet concentration, while that of $k^{\prime}$ increases. The value of $k$, on the other hand, is theoretically independent of adsorbate inlet concentration. This is fairly well-demonstrated by the experimental results in this study. It is noted that different adsorbents are characterized by different values of $k$. The values of $k$ are $12.88 \pm 0.77$ and $11.59 \pm 1.73$ for adsorbents PCB and BPL, respectively. Data from the nitrogen adsorption-desorption isotherms of these adsorbents at $77 \mathrm{~K}$ provide an indication of the wide mouth-like shape of the pore as well as of the considerable micropore volume [25]. The pore size distributions obtained for the activated carbons reveal that the micropore surface area $\left(853 \mathrm{~m}^{2} / \mathrm{g}\right)$ and micropore volume $\left(0.407 \mathrm{~cm}^{3} / \mathrm{g}\right)$ of adsorbent PCB are greater than those (i.e. $621 \mathrm{~m}^{2} / \mathrm{g}$ and $0.286 \mathrm{~cm}^{3} / \mathrm{g}$ ) of adsorbent BPL. As expected, the ratios (1.31-1.40) of the values $\tau$ of adsorbent PCB to adsorbent at the same inlet concentration are very close to the ratio of the micropore volume (1.43) or micropore surface area (1.37) of adsorbent PCB to that of adsorbent BPL.

Following the determination of $\tau$ and $k^{\prime}$, one can easily construct the complete breakthrough curves for a given set of experimental conditions by applying Eq. (9) and

Table 4

Values of the parameters $\tau, k^{\prime}$, and $k$ for HCFC-141b adsorption on adsorbents PCB and BPL at various inlet concentrations

\begin{tabular}{|c|c|c|c|c|c|}
\hline \multirow[t]{2}{*}{ Adsorbent } & \multirow[t]{2}{*}{ Concentration (ppm) } & \multicolumn{3}{|c|}{ Values of parameters } & \multirow[t]{2}{*}{$R^{2}$} \\
\hline & & $\overline{\tau(\min )}$ & $k^{\prime}\left(\min ^{-1}\right)$ & $k$ & \\
\hline \multirow[t]{6}{*}{$\overline{\mathrm{PCB}^{\mathrm{a}}}$} & 351 & 190.2 & 0.0706 & 13.43 & 0.9956 \\
\hline & 807 & 116.9 & 0.1119 & 13.08 & 0.9848 \\
\hline & 1153 & 85.3 & 0.1434 & 12.24 & 0.9987 \\
\hline & 1522 & 62.2 & 0.2048 & 12.74 & 0.9918 \\
\hline & 1946 & 49.9 & 0.2583 & 12.89 & 0.9935 \\
\hline & & & & $\begin{array}{l}\text { mean } \pm \text { standard } \\
\text { deviation }=12.88 \pm 0.44\end{array}$ & \\
\hline \multirow[t]{7}{*}{$\mathrm{BPL}^{\mathrm{b}}$} & 361 & 137.9 & 0.1036 & 14.29 & 0.9947 \\
\hline & 792 & 85.0 & 0.1539 & 13.08 & 0.9989 \\
\hline & 1140 & 60.8 & 0.1649 & 10.03 & 0.9977 \\
\hline & 1537 & 47.6 & 0.2257 & 10.74 & 0.9860 \\
\hline & 1962 & 36.6 & 0.2679 & 9.81 & 0.9838 \\
\hline & & & & mean \pm standard & \\
\hline & & & & deviation $=11.59 \pm 1.99$ & \\
\hline
\end{tabular}

\footnotetext{
${ }^{\mathrm{a}}$ The weight used in this study is $3.05 \pm 0.01 \mathrm{~g}$.

${ }^{\mathrm{b}}$ The weight used in this study is $3.02 \pm 0.01 \mathrm{~g}$.
} 
using the determined values $\tau$ and $k^{\prime}$ (Table 4). The calculated breakthrough curves are compared with the corresponding experimental data as shown in Fig. 3. It is noted that each solid line in Fig. 3 represents the line of best fit. It can be seen that the agreement between model and experimental results is very satisfactory.
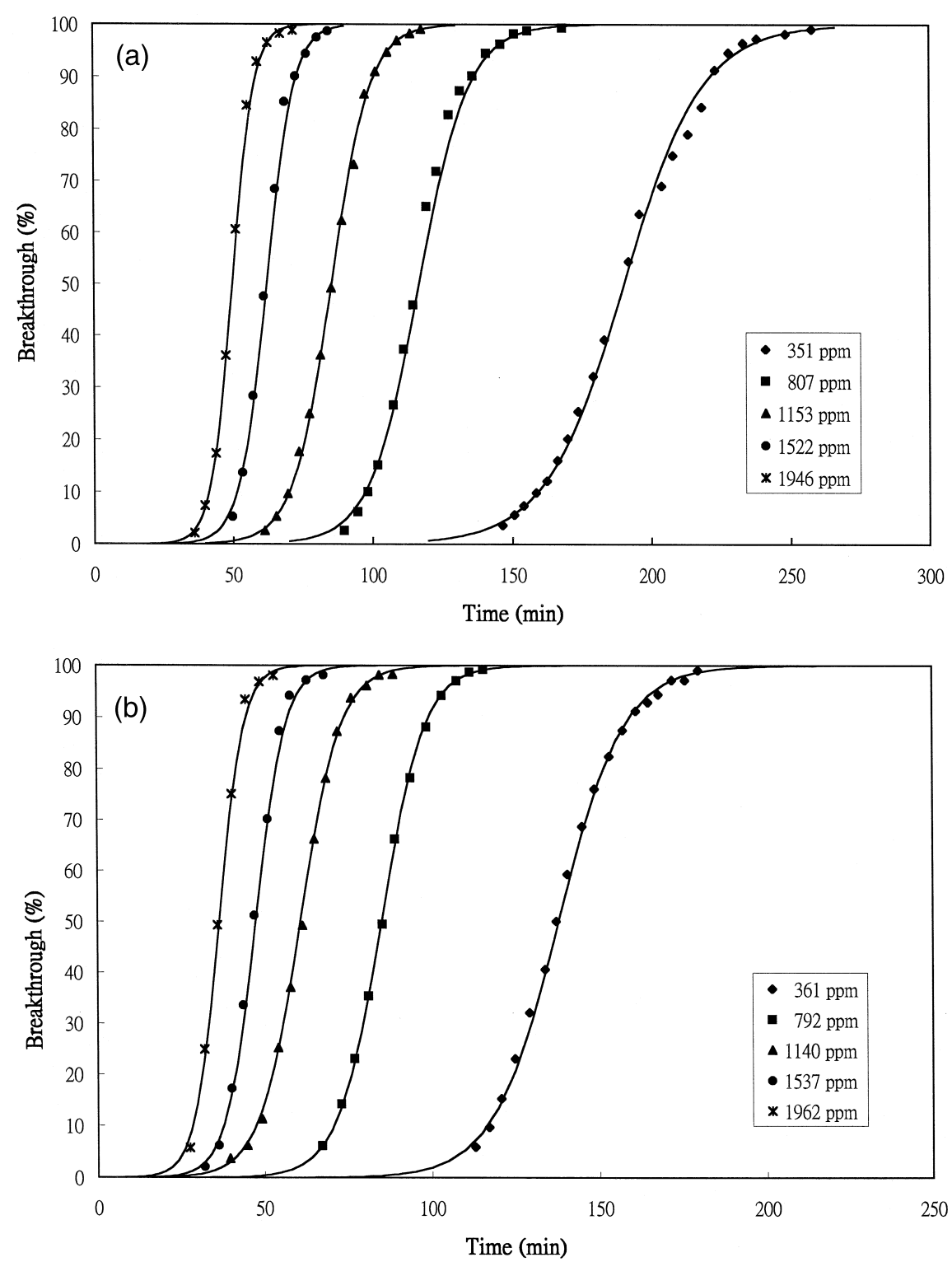

Fig. 3. Breakthrough curves for various concentrations of HCFC-141b adsorption on activated carbons (a) PCB and (b) BPL [symbols: experimental data; full lines: calculated from Eq. (9) and Table 4]. 


\section{Conclusions}

The adsorption characteristics of HCFC-141b on two commercial granular activated carbons (PCB made from coconut shell and BPL made from bituminous coal) were investigated. From the experimental results and data regression analysis, the adsorption isotherm obtained at various temperatures can be well-correlated by the Langmuir, Freundlich, and Dubinin-Radushkevich (D-R) models. It was found that the HCFC-141b adsorption capacity of adsorbent PCB is higher than that of adsorbent BPL, which is consistent with the measured physical properties (i.e. micropore surface area and micropore volume) of the adsorbents and computed model parameters of the isotherm equations. The simple two-parameter model (i.e. rate constant, $k^{\prime}$, and time required for $50 \%$ adsorbate breakthrough, $\tau$ ) of Yoon and Nelson was applied for modeling the breakthrough curves of HCFC-141b vapor through granular activated carbon column. The parameters obtained from the fitting of the experimental data with the model were used to generate theoretical breakthrough curves. The calculated theoretical breakthrough curves were in good agreement with the corresponding experimental data.

\section{Acknowledgements}

The authors express their sincere thanks to the National Science Council of Republic of China on Taiwan for the financial support under project number NSC 86-2211-E041003 .

\section{References}

[1] S.A. Montzka, R.C. Myers, J.H. Butler, J.W. Elkins, Geophys. Res. Lett. 21 (1994) 2483-2486.

[2] S.M. Schauffler, W.H. Pollock, E.L. Atlas, L.E. Heidt, Geophys. Res. Lett. 22 (1995) 819-822.

[3] J.M. Lee, W.T. Sturges, S.A. Penkett, D.E. Oram, U. Schmidt, A. Engel, R. Bauer, Geophys. Res. Lett. 22 (1995) 1369-1372.

[4] T.J. Wallington, W.F. Schneider, D.R. Worsnop, O.J. Nielsen, W.T. Debruyn, J.A. Schorter, Environ. Sci. Technol. 28 (1994) 320A-325A.

[5] G.D. Hayman, R.G. Derwent, Environ. Sci. Technol. 31 (1997) 327-336.

[6] S.H. Lin, Y.W. Chen, J. Environ. Sci. Health A 31 (1996) 1279-1292.

[7] W.T. Tsai, C.Y. Chang, H.C. Lee, J. Environ. Sci. Health A 31 (1996) 995-1008.

[8] M.W. Anders, Environ. Health Perspect. 96 (1991) 185-191.

[9] R. Rubenstein, Toxicol. Lett. 68 (1993) 21-24.

[10] J.J. Spivey, Environ. Prog. 7 (1988) 31-40.

[11] C.S. Parmele, W.L. OConnell, H.S. Basdekis, Chem. Eng. 75 (1979) 58-70.

[12] M.J. Ruhl, Chem. Eng. Prog. 89 (1993) 37-41.

[13] J.R. Graham, M. Ramaratnam, Chem. Eng. 99 (1993) 6-12, Suppl.

[14] K.E. Noll, V. Gounaris, W.S. Hou, Adsorption Technology for Air and Water Pollution Control, Lewis, Chelsea, MI, USA, 1991.

[15] L. Sorrento, Chem. Eng. 100 (1994) 94-95.

[16] K.S. Knaebel, Chem. Eng. 101 (1995) 92-102.

[17] R.C. Bansal, J.B. Donnet, F. Stoeckli, Active Carbon, Marcel Dekker, New York, NY, USA, 1988.

[18] H.F. Stoeckli, Carbon 28 (1990) 1-6. 
[19] P.B. Logsdon, R.S. Basu, Recovery and Recycle of HCFCs by Activated Carbon Adsorption, Proc. of the 38th Annual Meeting of the Institute of Environmental Sciences, Nashville, TN, USA, pp. 482-489.

[20] S.H. Lin, Y.W. Chen, J. Hazard. Mater. 57 (1998) 193-203.

[21] S.H. Lin, Y.W. Chen, J.K. Huang, Adsorpt. Sci. Technol. 13 (1996) 187-195.

[22] S. Tanada, N. Kawasaki, T. Nakamura, I. Abe, J. Colloid Interface Sci. 183 (1996) 143-147.

[23] J. Benitez, Process Engineering and Design for Air Pollution Control, Prentice-Hall, Englewood Cliffs, NJ, USA, 1993.

[24] G.O. Wood, E.S. Moyer, Am. Ind. Hyg. Assoc. J. 52 (1991) 235-242.

[25] W.T. Tsai, C.Y. Chang, J. Chem. Technol. Biotechnol. 61 (1994) 145-151.

[26] Y.H. Yoon, J.H. Nelson, Am. Ind. Hyg. Assoc. J. 45 (1984) 509-516.

[27] D.M. Ruthven, Principles of Adsorption and Adsorption Process, Wiley, New York, NY, USA, 1984.

[28] M. Suzuki, Adsorption Engineering, Elsevier, Amsterdam, the Netherlands, 1990.

[29] M.S. Chou, J.H. Chiou, J. Environ. Eng. (ASCE) 123 (1997) 437-443.

[30] J.M. Smith, Chemical Engineering Kinetics, 3rd edn., McGraw-Hill, New York, NY, USA, 1981.

[31] C.N. Satterfield, Heterogeneous Catalysis in Industrial Practice, 2nd edn., McGraw-Hill, New York, NY, USA, 1991.

[32] A.W. Adamson, Physical Chemistry of Surfaces, 5th edn., Wiley, New York, NY, USA, 1990.

[33] S.J. Gregg, K.S.W. Sing, Adsorption, Surface Area and Porosity, 2nd edn., Academic Press, New York, NY, USA, 1982.

[34] P.J. Reucroft, W.H. Simpson, L.A. Jonas, J. Phys. Chem. 75 (1971) 3526-3531.

[35] D.R. Lide, CRC Handbook of Chemistry and Physics, 78th edn., CRC Press, Boca Raton, FL, USA, 1997.

[36] Y. Maezawa, H. Sato, K. Watanabe, J. Chem. Eng. Data 36 (1991) 409-413.

[37] A.T. Sousa, P.S. Fialho, C.A. Nieto de Castro, Int. J. Thermophys. 15 (1994) 375-377.

[38] G.O. Wood, Am. Ind. Hyg. Assoc. J. 48 (1987) 703-709.

[39] G.O. Wood, E.S. Moyer, Am. Ind. Hyg. Assoc. J. 50 (1989) 400-407.

[40] A. Wheeler, A. Robell, J. Catal. 13 (1963) 299-313.

[41] I.M. Klotz, Chem. Rev. 39 (1946) 241-246. 